\title{
Approbation of the theory of fractals and damageability of rocks when solving geomechanical problems
}

\author{
Oleh Riabtsev ${ }^{1, *}$, and Serhii Protsak ${ }^{1}$ \\ ${ }^{1}$ Institute of Geotechnical Mechanics named by N. Poljakov of National Academy of Sciences of \\ Ukraine, 49005, Dnipro, Simferopolska Str., 2a, Ukraine
}

\begin{abstract}
The results of a comprehensive geomechanical prediction of the state of the host rocks in the vicinity of the development working when mining the excavation column of longwall in the vicinity of the rock inrush in the conditions of one of the mines of Western Donbas are presented. A numerical simulation of the size and shape of the rock inrush zone and a comparison of the obtained results with the full-scale mine observations were carried out using the theory of fractals and rock damageability.
\end{abstract}

\section{Introduction}

Works in mines are extremely complicated by the lack of sufficient knowledge about the structure and properties of rocks, which are often saturated with gas and often flooded, tectonically broken and are under high compressive stresses, displacement processes during mining operations.

Since coal reserves suitable for mining are exhausted, the rationalization of technical solutions aimed at reducing forced coal losses in various types of pillars are topical. Such solutions can increase the economic and production efficiency of mining sites. In particular, when mining lava through the seam c6 of one of the mines of Zakhidnyi Donbas, as a result of inrush of the host rock in the assembly drift, part of the working came to an unsatisfactory condition. In addition, the development of the zone of inelastic deformations in the host rocks and the threat of repeated inrush do not make it possible to reuse this working for using the adjacent extraction column. Therefore, working the adjacent wall, it is necessary to pass the boundary entry to the collecting drift coal-cutting with stone, while ensuring minimal loss of coal in the pillar between the workings and a steady state of the mine for the smooth operation of the wall.

The width of the coal pillar in the development working coal-cutting with stone to the goaf is calculated in accordance with [1]. However, this method does not take into account the mining and geological factors in the form of dome folds and inrushes formed during mining, so in this case it cannot be used to obtain reasonable parameters of the width of the coal pillar between adjacent excavation pillars.

Based on the above, the justification of the technological pillar width between the collecting drift and the boundary entry of the adjacent excavation column, ensuring the

*Corresponding author: o.ryabtsev1973@gmail.com 
stability of the excavation column for the continuous operation of the wall with minimal coal losses in the pillar according to the geomechanical factor should be carried out through the use of methodology approved for mining and geological conditions in the mines of Zakhidnyi Donbas.

\section{Methodology for geomechanical forecast of the state of rocks in the vicinity of the mine workings}

To solve this scientific and applied problem, we used the methodology for determining rational technological parameters of mining operations, based on the provisions of the mechanism of displacement of a layered multi-modular rock mass [2]. This methodology has been developed by leading domestic mining scientists in relation to the mining and mining-technical conditions for mining coal deposits by underground mining in Ukraine. This methodology is implemented in the form of a software-technological complex "Technology of strategic planning of mining development", through which we choose the rational technological parameters while solving a specific mining engineering task [3].

This Technology has been successfully tested in all coal-mining areas - from Zakhidnyi Donbas with its unique mining and geological conditions, where host rocks have a weak degree of metamorphism, unstable, flooded, cracked, etc., to Skhidnyi Donbas, the conditions of which are characterized by a strong degree of host rocks metamorphism, a wide range of stability (from unstable to hard-to-crush), a large depth of working (over $1000 \mathrm{~m}$ ), as well as high gas-richness, etc. This technology makes it possible, at the design stage of mining, to carry out complex geomechanical forecasting of changes in the stressstrain state of the coal-rock massif and select rational technological parameters for mining that provide the maximum production and economic return for specific conditions [4].

There were two stages of numerical simulation of the geomechanical state of the coalrock mass. At the first stage, we consider the regularities of the stress-strain state (SSS) of rocks in the vicinity of the collecting drift in its working conditions, which are the following: a single working, that has been for some time outside the zone of influence of wall mining; excavation located in the zone of influence of wall mining; excavation located in the developed space of wall. The first stage of the studies makes it possible to define the minimum size of the coal pillar between the developed space of the wall and the boundary entry for working the adjacent wall, as well as assess the condition of the collecting drift. At the second stage, the features of the change in the SSS of the rock mass were investigated, taking into account the boundary drift, which made it possible to forecast its state up to maturity following the movement of wall.

Studies of the SSS change of the rock mass were carried out taking into account changes in the geological conditions along the extraction column of wall, according to the data of geological exploration wells and geological forecast. In this article, we focus on the results obtained for the conditions of a geological exploration well, where a host rock inrush occurred in the collecting drift, which is the main complicating factor for substantiating the size of the coal pillar. Numerical modeling of the inrush zone of the host rocks in the vicinity of the collecting drift was carried out using the theory of fractals [5] and damage to rocks [6]. This approach tests this methodology in solving practical mining engineering problems.

\section{Results of numerical modeling of basic geomechanical processes}

The studies of the main geomechanical processes in the surrounding rocks in the vicinity of 
the collecting drift outside the zone of wall influence show that active geomechanical processes take place for about 250 days from the time of the working. In future, changes in the parameters of the reference zone will be minimal.

The width of the supporting zone varies from $4.5 \mathrm{~m}$ at the moment of the beginning of its formation and reaches $8.0 \mathrm{~m}$ at the moment of attenuation of the main geomechanical processes. The maximum values of normal loads are concentrated in the area up to $3 \mathrm{~m}$ from the boundary of the working contour, where the zone of inelastic deformations in rocks has been developed.

The results of numerical modeling of changes in the stress-strain state of the host rocks in the vicinity of the collecting drift in the zone of influence before the conjugation by wall show that the zone of influence of wall extends approximately $38 \mathrm{~m}$ deep into the massif, both in the direction of wall movement and away from it (in the field adjacent extraction post). The maximum normal load in the reference zone is about $32000 \mathrm{kN}$ and is located at a distance from 2 to $4 \mathrm{~m}$ deep in the massif.

Figure 1 shows the results of numerical modeling of formation process of a stationary support zone near the boundaries of the collecting drift under mining the $c_{6}$ wall layer depending on the distance of the wall escape $L$ from the section under consideration.

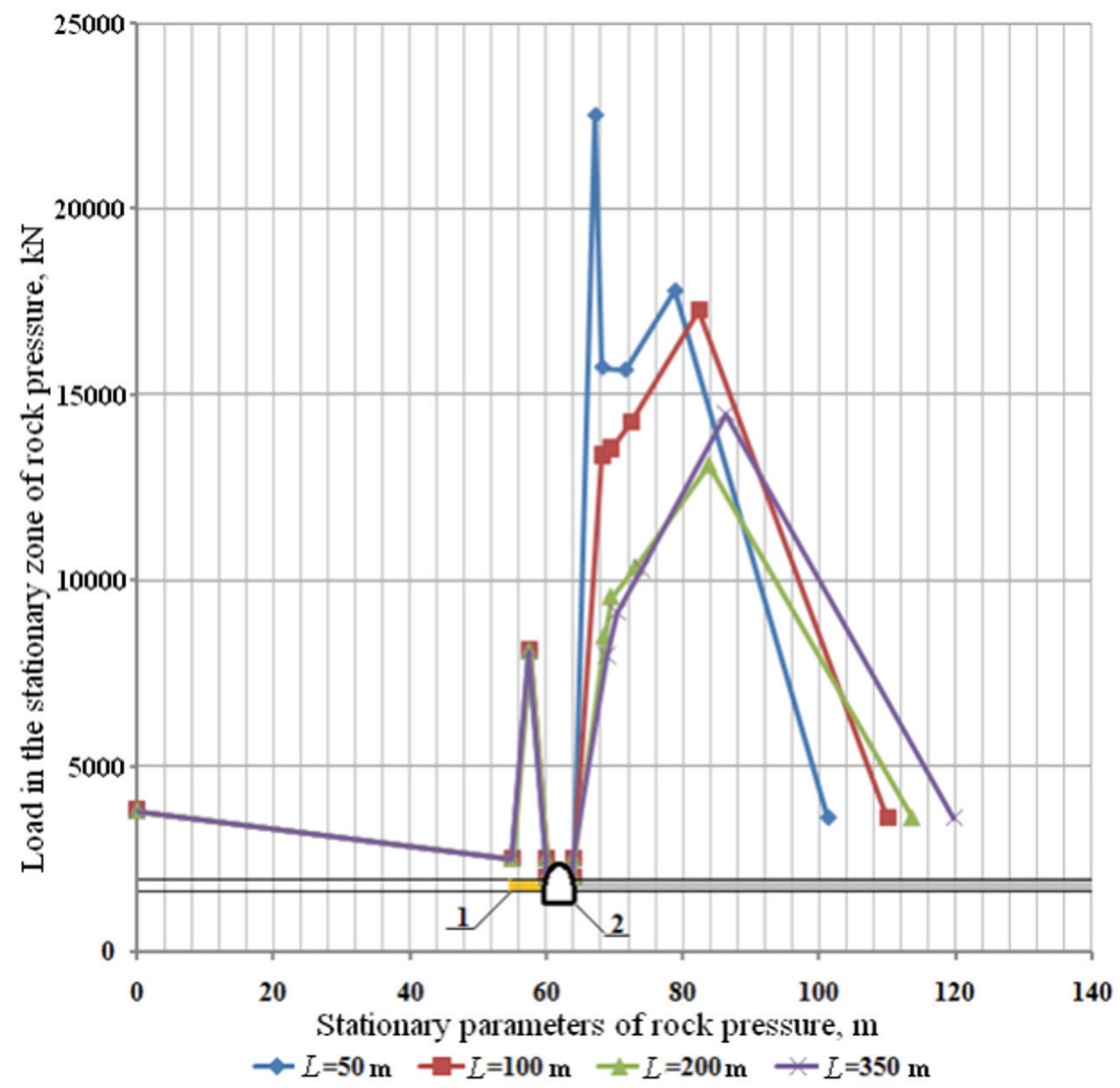

Fig. 1. Parameters of the stationary zone of rock pressure depending on the wall escape $L: 1$ - security structure from the side of the wall; 2 - collecting drift. 
The modeling wall escape value was changed until the difference between the corresponding parameters was less than $5 \%$, which indicates the attenuation of active geomechanical processes and the final formation of the boundaries of the stationary support zone.

According to the research, the maximum normal load decreases from $22500 \mathrm{kN}$ under the wall escape $50 \mathrm{~m}$ to $14500 \mathrm{kN}$ under the wall escape $350 \mathrm{~m}$. At the same time, which is of particular interest, the maximum of the stationary support zone with the $\mathrm{w}$ wall escape up to $50 \mathrm{~m}$ is at a distance of $3.2 \mathrm{~m}$ from the working contour at the level of the immediate roof layers, which will cause its destruction down to the coal seam $\mathrm{c}_{6}{ }_{6}$. According to calculations, in order to keep the weight of the collapsed rocks, it is necessary to have a fastening density of the order of 5 frames per meter, otherwise the roadway support will be deformed. And when soaking rocks of the soil, which lose their carrying capacity, the support bars is pressed into the soil until the roof closes with the soil. After the destruction of the layers of the roof, the maximum of the stationary support zone moves deep into the massif to $22.3 \mathrm{~m}$, and the width of the zone will increase to $55.7 \mathrm{~m}$.

As a result of research, the obtained values of the distribution of the inelastic deformation zone deep into the massif in the vicinity of the collecting drift are $3.1 \mathrm{~m}$ (excluding rock dump) and $6.5 \mathrm{~m}$ (including rock dump).

As mentioned above, the numerical modeling of the host rock inrush zone in the vicinity of the collecting drift was carried out using the theory of fractals and damageability of rocks. The results of this study are presented in Figure 2.

As a result, the use of the theory of fractals and damageability of rocks allowed us to obtain the geometric dimensions of the inrush zone until the final formation of this zone, which made it possible to comprehensively assess the geomechanical state of rocks in the vicinity of the collecting drift and substantiate the minimum required size of the technological pillar between this working and the boundary entry of adjacent wall.

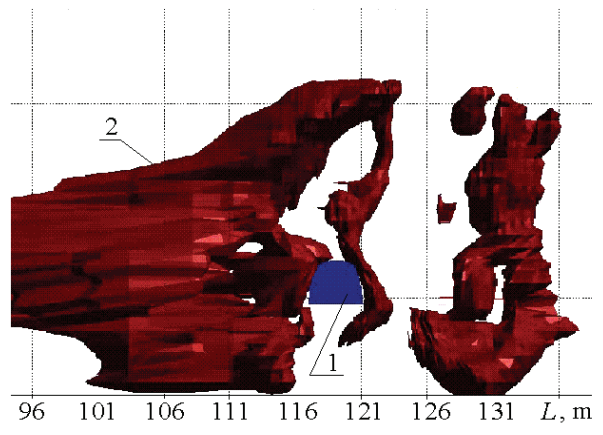

a)

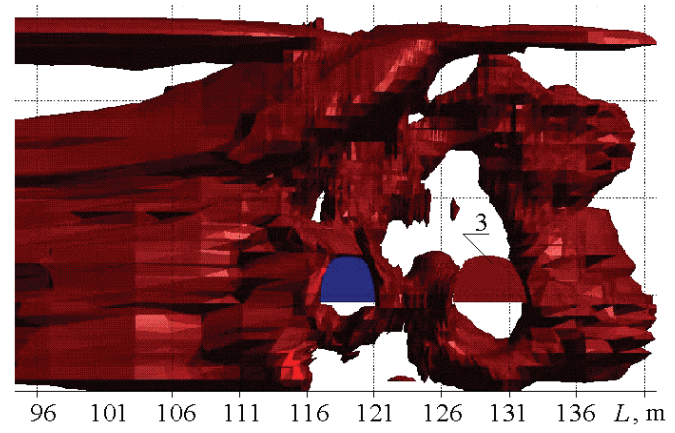

b)

Fig. 2. The tendency to form a zone of inelastic deformations of rocks in the stationary zone of rock pressure: a) - at the time of the beginning of formation; b) - at the time of completion of the formation: 1 - collecting drift; 2 - zone of inelastic deformations of rocks; 3 - boundary entry of adjacent wall.

Figure 2a shows that at the beginning of the formation of a stationary support zone in the vicinity of the collecting drift in the rocks of the roof and soil, an unbroken rock mass is still preserved, which allows maintaining working in a satisfactory condition. Although in the field of the adjacent excavation column at a distance of $8-10 \mathrm{~m}$ from the working boundary in the zone the concentration of maximum loads in the support zone, the formation of a zone of inelastic deformations is observed. By the completion of the formation of the stationary zone of rock pressure (Fig. 2b), the rocks in the roof and the soil of the collecting drift are completely disintegrated to a height of 11-15 $\mathrm{m}$ and stretch to $15-$ 
$20 \mathrm{~m}$, which caused the inrush of rocks to the mine. In addition, the dimensions of the inelastic deformation zone in the stationary zone of high rock pressure slightly increased. However, at a distance of 6-7 m from the boundary of the drift, a zone of steady state of the roof rocks and soil is predicted, which is enough to hold an airborne drift in it and to work out the adjacent extraction column. Thus, the results of studies carried out using the theory of fractals and damageability correlate well with the results of studies performed using [3] in order to substantiate the width of the technological pillar between adjacent excavation fields in complex mining, geological and engineering conditions, where the additional complicating factor is inrush of soil rocks into working.

\section{Comparison of numerical simulation results with mine field studies}

As the boundary entry operated, visual and instrumental observations were continuously conducted in order to define changes in its condition and verify the accuracy of the predicted residual height. Figure 3 shows the height of the boundary entry based on the results of surveys, and the corresponding forecast values presented during the work before the start of the working.

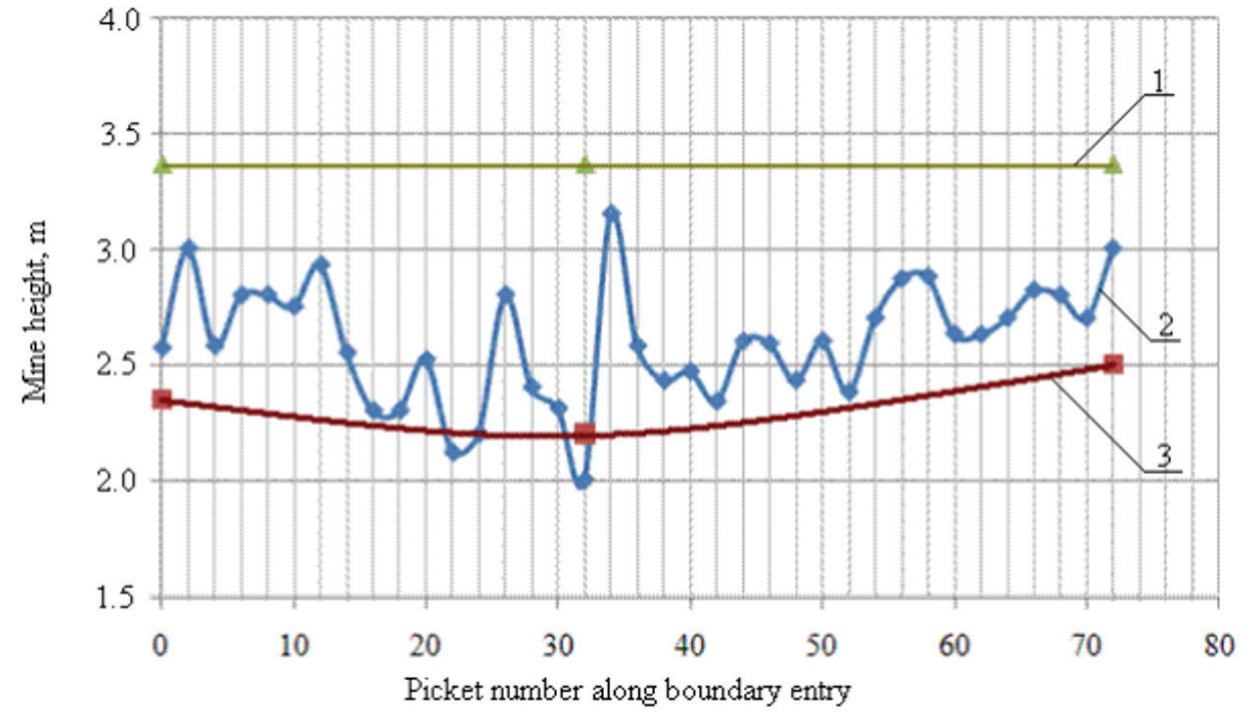

Fig. 3. Comparison of the results of numerical modeling of the boundary entry height with the results of full-scale measurements in the mine: 1 - design height of working during its implementation, $\mathrm{m} ; 2$ - actual measurement of height, $\mathrm{m} ; 3$ - height values obtained by numerical modeling, $\mathrm{m}$.

According to Figure 3, the average actual height of working is $2.6 \mathrm{~m}$ with a predicted $2.35 \mathrm{~m}$, so, the average deviation of the predicted values from the actual does not exceed $10 \%$ with a maximum deviation of $25.4 \%$. The average cross-section of working is $7.7 \mathrm{~m}^{2}$ means that the working is in good condition and fully performs its functional purposes. A visual inspection of the working confirms the fact that practically all along its length, there are no deformations of the support elements, even in the danger zone adjacent to the inrush, due to chemical anchoring. The visual condition of the boundary drift in the most unfavorable area for its maintenance (the area of the rock outfall) is shown in Figure 4. 
Instrumental measurements of the rock inrush zone showed that the height of the dome formed by the inrush was about $12 \mathrm{~m}$, the maximum width was up to $6.5 \mathrm{~m}$ and the length of the stretch of working was up to $15 \mathrm{~m}$, which well coincides with the results of numerical modeling of the size of this area using the theory of fractals and damageability.

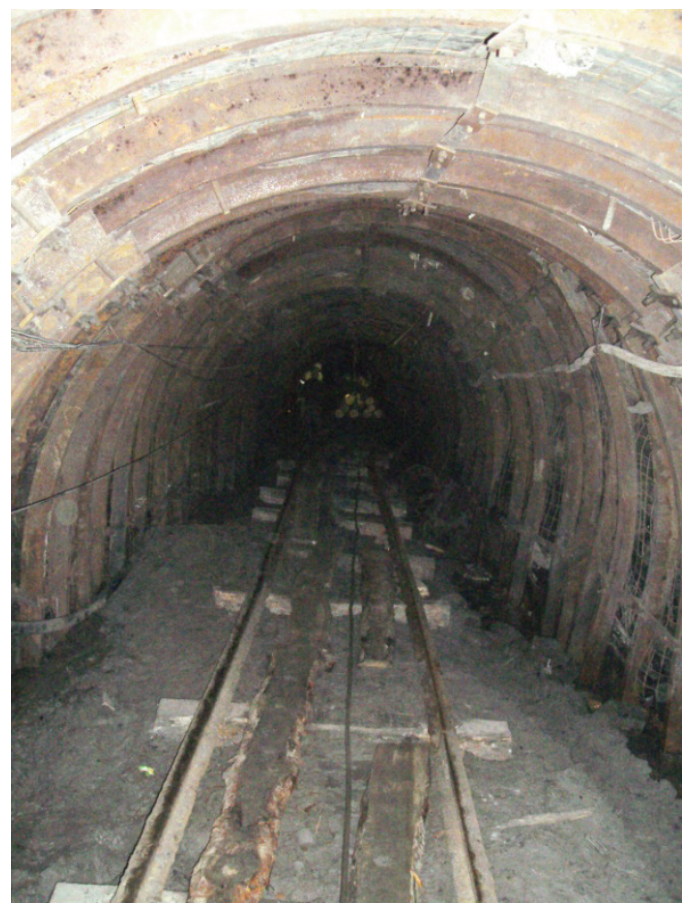

Fig. 4. Boundary entry condition in the most unfavorable area for its maintenance (the area of rock inrush).

\section{Conclusions}

The results of numerical modeling of the stress-strain state of rocks in the vicinity of the collecting drift using [3] made it possible to determine the minimum dimensions of the coal pillar between the roadway of wall and boundary entry of the adjacent extraction column by geomechanical factor. Studies allow to assess the state of development workings, in particular, the magnitude of convergence, which made it possible to offer some practical recommendations for improving the conditions for maintaining the boundary entry with minimal operating costs. The complex of studies using the theory of fractals and the damageability of rocks allowed to determine the minimum possible parameters of the pillars for carrying the boundary drift outside the zone of inelastic deformations of the coalrock massif formed during the extraction of longwall. This made it possible, in addition to minimizing the loss of coal in the technological pillar, to avoid inrush of rock and coal into mining, to ensure the installation and operation of arch flexible lining in passport mode without premature deformation of its elements.

Instrumental and visual observations of the working showed that the average deviations of the predicted values of working height do not exceed $10 \%$ of the actual ones, measured during surveying. This indicates a high accuracy of predicted values. A good correlation between the values of the size of the inelastic deformation zone, obtained using [3] and the theory of fractals and the damageability of rocks, makes it possible to use this theory in solving complex geotechnical geomechanical problems. 


\section{References}

1. Industry Standard Ukraine 10.1.00185790.011:2007. (2007). Pidhotovchi vyrobky na polohykh plastakh, vybir kriplennya, sposobiv i zasobiv okhorony. Kyiv: Minvuhleprom Ukrainy

2. Voloshyn, A.I., Bulat, A.F., Ryabtsev, O.V., Koval, A.I. (2010). Metodologiya opredeleniya ratsional'nykh tekhnologicheskikh parametrov vedeniya gornykh rabot. Ugol Ukrainy, (10), 15 - 18

3. Voloshyn, A.I., Bulat, A.F., Ryabtsev, O.V., Savostiyanov, A.V. (2011). Tekhnologiya strategicheskogo planirovaniya razvitiya gornykh rabot. Ugol, (2), $22-25$

4. Voloshyn, A.I. (2013). Tekhnolohyya stratehycheskoho planyrovanyya razvytyya hornykh rabot. Materialy naukovo-praktychnoho seminaru «Stratehichne planuvannya rozvytku hirnychykh robit», $m$. Donetsk, 29.01.2013. DU «NNDIPBOP» Informatsiynyy byuleten z okhorony pratsi, (1), $52-69$

5. Bulat, A.F., Dyrda, V.I. (2005). Fraktaly v geomekhanike. Kyiv: Naukova Dumka

6. Voloshyn, A.I., Ryabtsev, O.V., Morozov, Yu.A. (2017). Modelirovaniye protsessa razrusheniya gornykh porod po parametru povrezhdayemosti. Ugol Ukrainy, (1-2), 61-67 